\title{
Photocatalytic abatement of o-xylene using adsorption enhanced ZnO/GAC catalyst in a continuous flow reactor: Catalytic potential, Fate of o-xylene and its by-products
}

\author{
Ahmad Jonidi Jafari ${ }^{1,2}$, Majid Kermani², Roshanak Rezaei Kalantary² and Hossein Arfaeinia ${ }^{2, *}$ \\ ${ }_{1}^{1}$ Research Center for Environmental Health Technology, Iran University of Medical Sciences, Tehran, Iran \\ 2Department of Environmental Health Engineering, School of Public Health, Iran University of Medical Sciences, Tehran, Iran \\ Received: 10/03/2017, Accepted: 10/03/2017, Available online: 22/10/2017 \\ *to whom all correspondence should be addressed: e-mail: arfaeiniah@yahoo.com
}

\begin{abstract}
Photocatalytic abatement of o-xylene was investigated by immobilized $\mathrm{ZnO}$ on granular activated carbon (ZnO/GAC) under UV irradiation. Immobilization of $\mathrm{ZnO}$ increased the breakthrough time and removal capacity by 51 and 57\%, respectively, in optimal conditions. The catalytic potential of the ZnO/GAC (86.5\%) for o-xylene removal was far greater than simple GAC (13.5\%), at the optimum condition. The maximum removal capacity with $\mathrm{ZnO} / \mathrm{GAC}$ (3.12g o-xylene /gZnO/GAC) was observed at $100{ }^{\circ} \mathrm{C}$, while the maximum removal capacity of simple GAC (1.37 g oxylene/g GAC) was observed a $t 20{ }^{\circ} \mathrm{C}$. The main intermediates of the o-xylene oxidation in photocatalytic process with GAC were methanoic acid, o-nitro-p-cresol, phenylmethanal, and methyl di-phenyl-methane. ZnO/GAC can highly catalyze the degradation of o-xylene in the presence of UV, with methanoic acid being the major intermediate desorbed from the bed. The results demonstrated that the $\mathrm{ZnO} / \mathrm{GAC}$ is an efficient option for the removal of VOCs and biohazards emitted from industrial streams.
\end{abstract}

Keywords: Volatile organic compounds (VOCs), O-xylene, Photocatalyst, Zinc Oxide(ZnO), Granular Activated Carbon(GAC)

\section{Introduction}

Volatile organic compounds (VOCs) are primary pollutants in atmosphere characterized by a high vapour pressure at about room temperature $\left(>0.01 \mathrm{kPa}\right.$ at $\left.20^{\circ} \mathrm{C}\right)$, favoring their transfer from liquid/solid emission origins to the atmospheric air (Adjimi et al., 2014). Atmospheric VOCs can be generated by variety of industrial and commercial activities such as oil supplying, transportation, use of paints, polymers synthesis, metal degreasing, domestic activities, etc. (Arfaeinia et al., 2015; Assadi et al., 2014; Barzegar et al., 2014). Exposure to VOCs might cause headache, fatigue, irritation of respiratory tract, dizziness and nausea, skin irritation, rhinitis, and also toxic effects to the nervous system (Auvinen and Wirtanen, 2008; Mirzaei, 2016; Mo et al., 2009). Moreover, some VOCs derived from aromatic molecules such as BTEX (benzene, toluene, ethylbenzene, and o-xylene s) can have mutagenic and carcinogenic effects on humans (Tunsaringkarn et al., 2012). The intrinsic hazard of VOCs to public health and the environment has motivated investigations into finding a new technique for reducing and, if possible, removing these hazardous pollutants.

Some conventional techniques have been proposed to eliminate VOCs emissions including adsorption (Boulinguiez and Le Cloirec, 2010), condensation (Dunn and El-Halwagi, 1994), thermal incineration(Le Cloirec and Germinet, 1998), combustion (Maldonado-Hódar, 2011), and biofiltration (Wang et al., 2010). However, these techniques have some limitations such as costineffectiveness and operational difficulty especially in the cases where low concentrations of VOCs (less than 100 ppm) are required to be treated (An et al., 2011). Thus, these methods are not very satisfying and do not meet current strict social requirements. Photocatalytic systems are the most effective and economical way which do not have the above mentioned limitations and can be used in a wide range of concentrations and gas flow rates (Özçelik et al., 2009). In this technique, a semi-conductor photocatalyst is activated by photons generated by a UV radiation lamp (sunlight or UV lamps) (Assadi et al., 2013; Bouzaza et al., 2006). It is proved that this technique has the ability to abate a large number of VOCs with a low energy consumption (Assadi et al., 2014; Pichat et al., 2000). Therefore, it seems to be a suitable method for treatment of air polluted by VOCs.

The practical utilization of metal oxide catalysts in photocatalytic processes needs the development of highly porous supports allowing an appropriate dispersion of immobilized metal oxide nanoparticles, a good conductance of UV radiation to the active sites, and a high adsorbing capacity (Adjimi et al., 2014). Various porous materials have recently been used as a support for $\mathrm{TiO}_{2}$ and other nanoparticles, including silica (e.g., glass, quartz, optical fibers (Danion et al., 2004), molecular sieves (Choi et al., 2001)), porous polymers (Wu and Chang, 1998), clay (Kibanova et al., 2009), stainless steel (Candal et al., 2000), 
carbon fibers (Herbig and Löbmann, 2004), activated carbon (Ao and Lee, 2005), zeolite (Ichiura et al., 2002), alumina (Ding et al., 2001), and cellulose fibers (Uddin et al., 2007). Amongst them, Granular activated carbon (GAC) can be the most suitable adsorbent and catalyst support. A good designed GAC adsorption system can eliminate VOCs to non-detectable levels from the polluted air (Granda et al., 2003), mainly due to high adsorbing capacity, high surface area and macro-size pore distribution (Das et al., 2004). In addition, both of the GAC and VOCs are basically hydrophilic and therefore encourage the interaction of VOC molecules toward the carbon surface (Kwong et al., 2008a; Shepherd, 2001). Moreover, GAC can be used as catalyst support without a considerable decreeing of its BET surface and pore volume (El-Sheikh et al., 2004). Furthermore, it is reported that the pores of GAC are not blocked by the agglomeration of photocatalyst particles and there is a proportion between the pore volume reduction of GAC and its amount in the catalyst (Puma et al., 2008). Thus, it will be possible to take advantage of both adsorption and catalytic degradation processes by impregnating GAC with an efficient catalyst agent.

Accordingly, in the present study, the capabilities of GAC and GAC impregnated with $\mathrm{ZnO}$ as catalyst were investigated in a photocatalytic system for the removal of a model VOC, o-xylene, from polluted air in a continuoustype reactor. O-xylene was selected as the VOC model because it is one of the most common VOCs in occupational and industrial settings, highly toxic for human health and is listed as a hazardous air pollutant (HAP) by EPA (EPA). Moreover, the influence of some important operational variables including inlet o-xylene concentration and flow rate, empty bed contact time (EBCT) and bed temperature of the catalyst was studied on the photocatalytic abatement of o-xylene in a continuous flow reactor with $\mathrm{GAC}$ and $\mathrm{ZnO} / \mathrm{GAC}$ as catalysts. In addition, the catalytic potential of $\mathrm{ZnO} / \mathrm{GAC}$ was measured on the removal of oxylene. Finally, the fate of the o-xylene on the GAC and $\mathrm{ZnO} / \mathrm{GAC}$ adsorbents was investigated.

\section{Materials and methods}

\subsection{Materials}

The GAC used in this work was supplied from the Merck (Germany). To remove the impurities, GAC was thoroughly rinsed with distilled water before being employed as an adsorbent or as a support for $\mathrm{ZnO}$ and then dried at 100 for $24 \mathrm{~h}$. Charcoal adsorbent tube was purchased from SKC, London. All of the chloroform, o-xylene, chlorobenzene, acetyl acetone, diethanolamine, 2-propanol, ethanol, nitric acid, and zinc acetate dehydrate were of analytical grade and obtained from Merck (Germany).

\subsection{Synthesis and Immobilization of Zinc Oxide on GAC}

The granular activated carbon was used in current work with a mesh of $8 / 10$. The catalysts were prepared by Coprecipitation method by zinc chloride $(\mathrm{ZnCl} 2)$ precursors of $\mathrm{Zn}$ (Shirzad-Siboni et al., 2015). A stock solution $(\mathrm{pH}=6)$ of $0.1 \mathrm{~mol} / \mathrm{L}$ zinc chloride $(\mathrm{ZnCl} 2)$ was synthesized by dissolution of zinc chloride in distilled water. Then, GAC was added to the solution of zinc chloride with the ratio of 2:1 (w/w). After that, $0.2 \mathrm{M}$ sodium hydroxide solution was added dropwise to obtain an alkaline medium $(\mathrm{pH}=12)$, generating a white, gelatinous zinc oxide/GAC product. The produced mixture was placed under constant stirring for 7 h. The obtained product was then centrifuged, washed by distilled water 20 times and thereupon dried at $100^{\circ} \mathrm{C}$ in an oven for about $3 \mathrm{~h}$. The synthesized ZnO/GAC was thoroughly washed with distilled water for the elimination of free $\mathrm{ZnO}$ particles.

\subsection{Characterization Instruments}

The surface functional groups of the $\mathrm{ZnO}$ and $\mathrm{ZnO} / \mathrm{GAC}$ and catalysts materials were determined with a Fourier transform infrared spectroscopy (FTIR) analysis with a variation of $400-40001 / \mathrm{cm}$. Crystal structures of the composite materials were examined with XRD analysis. Debye-Scherrer formula was employed to determine the mean crystalline size of the prepared catalysts (Patterson, 1939). The morphology of the composites was visualized by Scanning electron microscopy (SEM) analysis. The chemical composition of the composites was quantified by energy dispersive analysis of $X$ - integrated into SEM rays (SEMEDAX). Eventually, specific surface area, and pore volume and pore size of the composites was quantified by nitrogen gas adsorption analyzer.

\subsection{Photocatalytic experimental set-up and procedure}

An annular Pyrex reactor was designed and constructed to investigate the photocatalytic removal of o-xylene using impregnated GAC catalyst. The internal diameter and length of the reactor were $65 \mathrm{~mm}$ and $65 \mathrm{~cm}$, respectively. Moreover, to place the UV lamp, a quartz cylinder was installed inside the reactor. The length and external diameter of the quartz cylinder were $55 \mathrm{~cm}$ and $55 \mathrm{~mm}$, respectively. The reactor was equipped with a stainlesssteel sheet with $6(\mathrm{~cm})$ diameter and 100-140 ASTM standard screen mesh at the bottom for uniform distribution of the gas flow and also to hold the catalysts.

The experimental setup consisted of a Pyrex cylinder with GAC and ZnO/GAC composites. The system of polluted air generation comprised of an air pump, a syringe pump, a mixing chamber, containers, connectors, tubing and fittings. To generate stable concentrations of o-xylene, all equipment and connectors were placed inside an isotherm box. The o-xylene vapor pressure depends on the temperature and, therefore, a heater thermostat was employed to adjust the temperature of the box. The bed temperature was adjusted with a thermocouple which was located in the middle of the catalyst column. The air flow was controlled at the favorable rate using a rotameter installed in the set-up. The liquid o-xylene was injected into the clean air stream with a syringe pump. After that, two gas streams were mixed in the mixing chamber to provide a favorable polluted stream and entered the reactor from the bottom. high-pressure Hg-lamp (Toshiba class, SHL100UVQ-2, 100W and $1.0-1.5 \mathrm{~mW} / \mathrm{cm}^{2}$ ) with a wave length range of $365-400 \mathrm{~nm}$ were used as a UV radiation source and placed in the center of the reactor in the same or opposite direction in relation to the inlet gas stream. The 
efficiency of GAC and ZnO/GAC for o-xylene removal from polluted air stream was analyzed under different initial oxylene concentrations of 80, 160, 240 and 360 ppm, catalyst dosage, residence times of $0.69,1,1.4,2.3$ and $6.9 \mathrm{~s}$, and bed temperatures of $20,50,80$ and $100{ }^{\circ} \mathrm{C}$. Replication of the experiments indicated that the standard deviations of the findings were less than $5 \%$. The experimental apparatus was continually inspected to be entirely gastight.

To measure the contribution of $\mathrm{ZnO}$ loaded on GAC in the catalytic potential of composites, the same mentioned runs were carried out with GAC as catalyst. The difference in the catalytic efficiency obtained between $\mathrm{ZnO} / \mathrm{GAC}$ with GAC was accounted for the $\mathrm{ZnO}$.

\subsection{Gas sampling and analysis}

For the sampling of o-xylene concentration in the polluted air, gas samples were taken from the outlet of the reactor with the charcoal adsorbent tube. Samples were taken by adsorbent tube coupled with sampling pump with an air flow of $0.2 \mathrm{~L} / \mathrm{min}$ at $25 \mathrm{~min}$. Desorption of the o-xylene samples was done using $\mathrm{CS}_{2}$ and subsequently its concentration was analyzed using a Gas Chromatograph, equipped with Flame Ionization Detector (FID) and capillary HP-5 column according to OSHA Laboratory Method No. 12

The efficiency of GAC, and ZnO/GAC catalysts for o-xylene removal was determined in terms of breakthrough time, removal capacity (RC), catalyst usage rate (CUR) and specific throughput (ST), according to following relations:

$$
\begin{aligned}
& R C=\frac{Q \cdot C \cdot T}{M} \\
& C U R=\frac{M}{C \cdot T} \\
& S T=\frac{C \cdot T}{M}
\end{aligned}
$$

Where, RC stands for the removed mass of o-xylene feed to the mass of catalyst until the breakthrough point time, $\mathrm{mg} / \mathrm{g} ; \mathrm{Q}$ is the air flow rate to catalysts, $\mathrm{m}^{3} / \mathrm{h} ; \mathrm{C}$ is the concentration of o-xylene, $\mathrm{mg} / \mathrm{m}^{3} ; \mathrm{T}$ denotes the breakthrough time (the time of being observed o-xylene in the exit gas stream), $\mathrm{h}$; and $\mathrm{M}$ is the mass of catalyst, $\mathrm{g}$.

\subsection{Evaluation of catalytic potential}

The catalytic performance of the GAC and $\mathrm{ZnO} / \mathrm{GAC}$ catalysts in o-xylene removal was investigated under optimum experimental conditions for each composite, based on the following relation:

$$
\text { Catalytic potential }=\left[\mathrm{T}_{\mathrm{UV}}-\mathrm{T}_{\mathrm{Ads}}\right]
$$

Where, $\mathrm{T}_{\text {Ads }}$ stands for the breakthrough time in the GAC and $\mathrm{ZnO} / \mathrm{GAC}$ beds in the adsorption runs (absence of UV), $h$, and Tuv denotes the breakthrough time of GAC, and $\mathrm{ZnO} / \mathrm{GAC}$ beds in the photocatalytic runs, $\mathrm{h}$.

\subsection{Fate of eliminated o-xylene and its by-products}

Desorption experiments were done to measure of the amount of destructed o-xylene and o-xylene oxidation intermediates with the GAC and ZnO/GAC in photocatalytic process. The photocatalytic experiments were operated using GAC and $\mathrm{ZnO} / \mathrm{GAC}$, each under its optimum experimental reaction time (i.e., $\mathrm{EBCT}=1 \mathrm{~s}$ ) and bed temperature (i.e., $100{ }^{\circ} \mathrm{C}$ for $\mathrm{ZnO} / \mathrm{GAC}$ and $20^{\circ} \mathrm{C}$ for GAC) until the breakthrough time was reached. After that, VOC loaded catalysts were agitated with $\mathrm{CS}_{2}$ for desorption of the o-xylene and oxidation intermediate species. Desorption was carried out based on NIOSH method NO. 1501(NIOSH, 2003). The concentration of o-xylene in the desorption solution was measured by Gas Chromatograph equipped with Flame Ionization Detector (FID) and capillary HP-5 column. The volume of injection was set to split ratio of $100: 1$. The $\mathrm{GC}$ oven initial temperature was set at $30^{\circ} \mathrm{C}$ and rose at a rate of $5{ }^{\circ} \mathrm{C} / \mathrm{min}$ until reaching $240{ }^{\circ} \mathrm{C}$. Detection of the type of generated by-products of the reaction was performed using GC, equipped with Mass Spectrometer (MS) detector and HP-5 capillary column, with GC temperature program conducted as mentioned previously.

\section{Results and discussion}

\subsection{Characterization of $\mathrm{ZnO}$ and Immobilized $\mathrm{ZnO}$ on GAC}

Since the photocatalytic reactions mainly happen on the photocatalyst surface, so the functional groups on it have a great role in its photocatalytic potential. FTIR analysis was conducted on GAC and $\mathrm{ZnO} / \mathrm{GAC}$ within the range of 400-4000 1/cm.

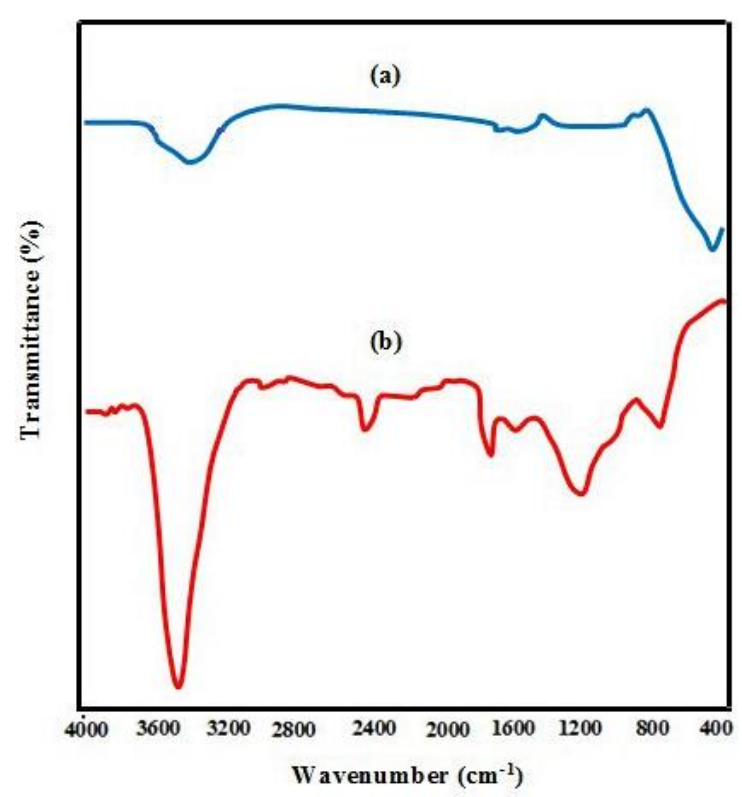

Figure 1. FT-IR image of samples; a) Pure GAC b) immobilized $\mathrm{ZnO}$ on granular activated carbon

Fig.1(a) and (b) indicate the active functional groups on the surface of the GAC and ZnO/GAC. FTIR spectrum of the ZnO/GAC demonstrates significant absorption peaks at 460, 730, 915 and 3500 1/cm. The band at 4601/cm belongs to $\mathrm{ZnO}$. This peak is seen in the FTIR patterns of immobilized $\mathrm{ZnO}$ on GAC as well. The band located at 
$710-8901 / \mathrm{cm}$ shows the existence of aromatic $\mathrm{C}-\mathrm{H}$ stretching and the band located at $35001 / \mathrm{cm}$ belongs to the hydroxyl groups $(-\mathrm{OH})$ (Darvishi Cheshmeh Soltani et al., 2013).

Fig. 2(a) and (b) show the XRD pattern of the GACand $\mathrm{ZnO} / \mathrm{GAC}$ catalysts. The peak positions at 2-theta of 32, 34 and 36 degrees are attributed to 100,002 and 101 planes of hexagonal wurtzite $\mathrm{ZnO}$, respectively. As shown in Fig. 2(b), the patterns indicate a good crystal structure of $\mathrm{ZnO}$ nanoparticles even after immobilization on GAC. The average crystallite size of $\mathrm{ZnO}$ nanoparticles was determined using the Debye-Sherrer's equation. Based on this equation, the mean crystal size of the $\mathrm{ZnO}$ and GACmodified $\mathrm{ZnO}$ was calculated as 56.4 and $54.1 \mathrm{~nm}$, respectively. This shows the insignificant influence of immobilization on the size of pure $\mathrm{ZnO}$ nanoparticles. This can be confirmed by reduction of total pore volume in the carbon upon coated with $\mathrm{ZnO}$ (Table 1).

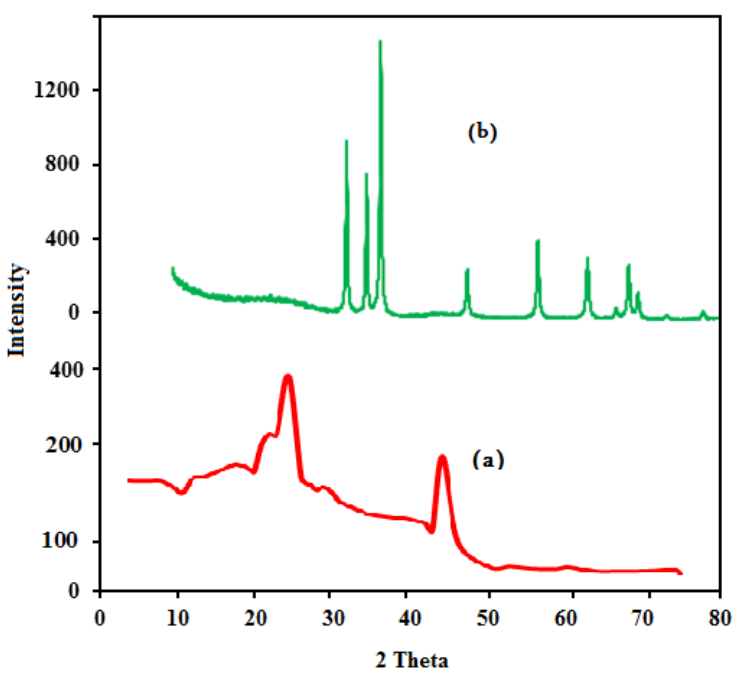

Figure 2. Typical XRD patterns of samples; a) Pure GAC b) immobilized $\mathrm{ZnO}$ on granular activated carbon

Table 1. Some features of GAC and the synthesized GAC/ZnO composite.

\begin{tabular}{cccc}
\hline \multirow{2}{*}{ Characteristics } & \multirow{2}{*}{ Unit } & \multicolumn{2}{c}{ Value } \\
\cline { 3 - 4 } & - & Micropore & Micropore \\
\hline Structure & $\mathrm{Nm}$ & 1.69 & 1.71 \\
\hline $\begin{array}{c}\text { Average pore } \\
\text { diameter }\end{array}$ & $\mathrm{m}^{2} / \mathrm{g}$ & 1209 & 1042 \\
\hline BET & - & 909.45 & 721.87 \\
\hline BET Constant & 281.67 & 241.43 \\
\hline $\begin{array}{c}\text { Monolayer } \\
\text { Volume }\end{array}$ & $\mathrm{cm}^{3} / \mathrm{g}$ & 0.5212 & 0.4471 \\
\hline $\begin{array}{c}\text { Pore Volume } \\
\text { (P/P0 =0.990) }\end{array}$ & $\mathrm{cm}^{3} / \mathrm{g}$ & 0.670 \\
\hline
\end{tabular}

Field emission scanning electronic microscopy (FE-SEM) images of pure GAC and ZnO/GAC were analyzed by a Mira microscope (Mira3, Tescan, Czech Republic). The obtained SEM images of the pure GAC and ZnO/GAC are depicted in Figs. 3a and b, respectively. As shown in Figs. 3a, the GAC has a heterogeneous and grainy textured surface (Liu et al., 2012). However, in GAC, the SEM image of ZnO/GAC indicates densely packed particles with less uncoated space. This is related to the grafting of $\mathrm{ZnO}$ nanoparticles onto GAC.

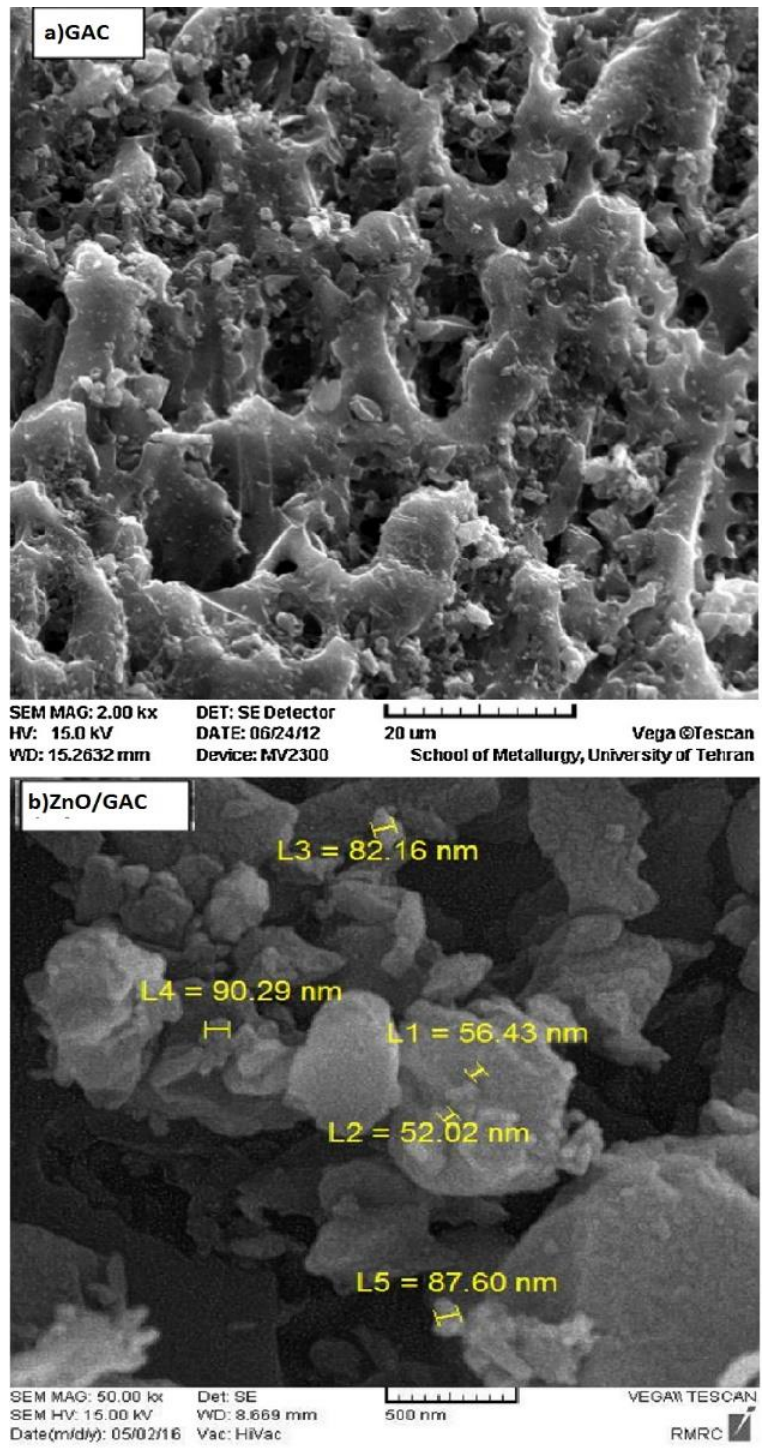

Figure 3. FESEM images of samples; a) Pure GAC b) immobilized $\mathrm{ZnO}$ on granular activated carbon.

EDX analyses were employed along with SEM to determine the chemical composition of the immobilized $\mathrm{ZnO}$ on GAC (Fig. 4). Based on Fig. 4, the percentage of $C$ and $O$ in the GAC was 98.12 and 1.67, and percentage of $C, Z n$ and $O$ in the $\mathrm{ZnO} / \mathrm{GAC}$ was series 45,34 and $11 \%$, respectively. Therefore, the presence of $\mathrm{ZnO}$ on the photocatalyst was proven.

The result of BET analysis about GAC and the ZnO/GAC catalysts are given in Table1. As shown in Table 1, the BET specific surface areas of GAC and the $\mathrm{ZnO} / \mathrm{GAC}$ catalysts were 1209 and $102 \mathrm{~m}^{2} / \mathrm{g}$, respectively, and pore volumes of GAC and the $\mathrm{ZnO} / \mathrm{GAC}$ catalysts were 0.5212 and 0.4471 $\mathrm{cm}^{3} / \mathrm{g}$, respectively. The dispersion of $\mathrm{ZnO}$ into the pore on GAC let to blocking those and consequently reduction in specific surface areas and pore volumes(Gaur et al., 2005). Arfaeinia et al. (Arfaeinia, 2016) also reported that metal oxides can reduce the BET area and the pore volume of the granular activated carbon. 


\subsection{O-xylene removal in photocatalytic process}

\subsubsection{Influence of initial o-xylene concentration}

The influence of initial o-xylene concentration from 80 to $360 \mathrm{ppmv}$ was studied on the efficiency of removal process at a fixed flow rate of $0.4 \mathrm{~L} / \mathrm{min}$ (i.e., contact time of $1 \mathrm{~s}$ ) at lab temperature $\left(20^{\circ} \mathrm{C}\right)$. Breakthrough curves are visualized in Fig. 5.

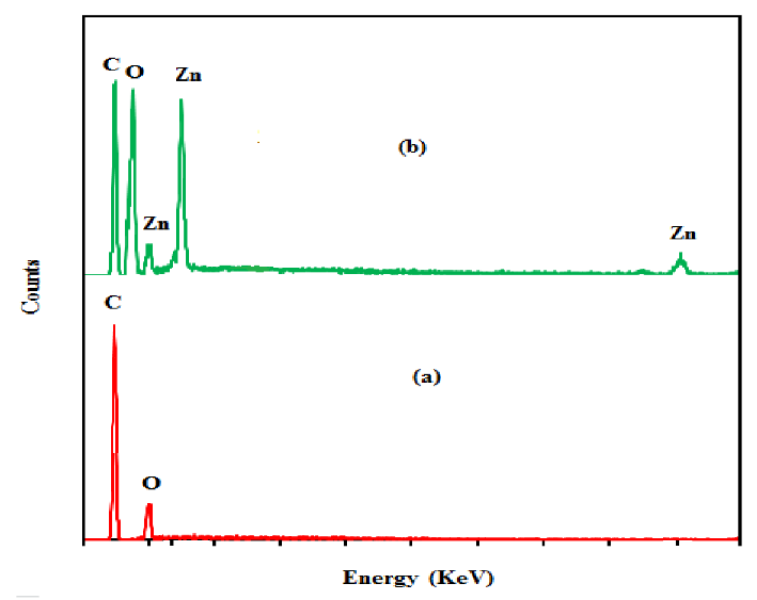

Fig.4. Typical EDX patterns of samples; a) Pure GAC b) immobilized $\mathrm{ZnO}$ on granular activated carbon.
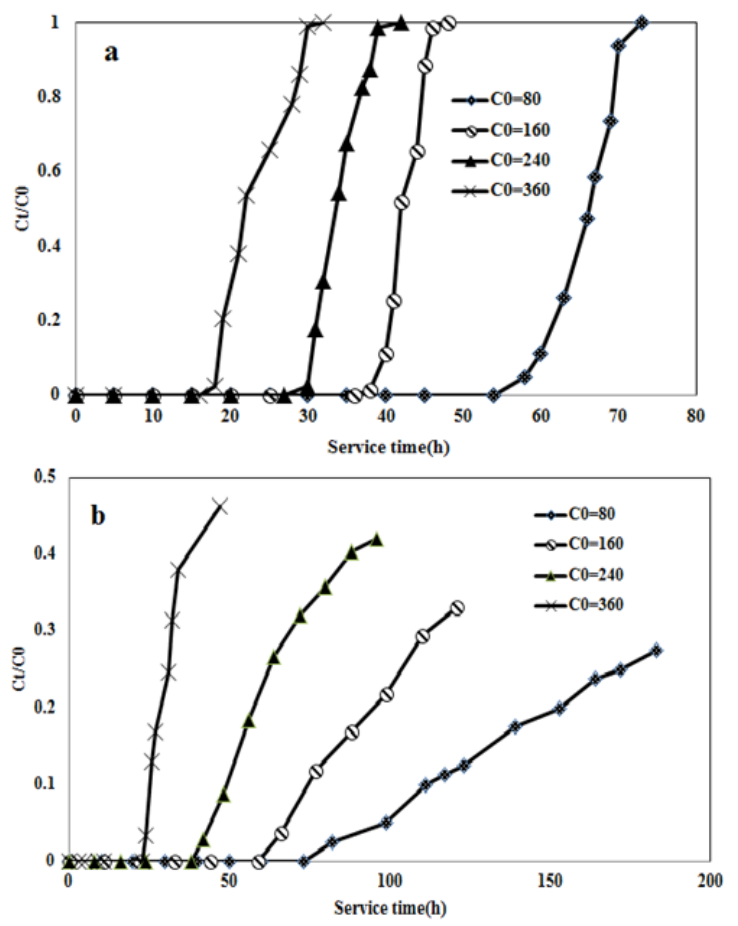

Figure 5. Influence of initial o-xylene concentration on the performance of (a) GAC and (b) ZnO/GAC (xperimental conditions: $\mathrm{EBCT}=0.69 \mathrm{~s} ; 1 \mathrm{~s}, 1.4 \mathrm{~s} ; 2.3 \mathrm{~s} ; 6.9 \mathrm{~s}$; initial oxylene concentration $=80 \mathrm{ppmv}$; bed temperature $=20^{\circ} \mathrm{C}$ )

As shown in Fig. 5, all curves of o-xylene eliminations in UVGAC column are S-shaped. The time of breakthrough in oxylene removal in UV-GAC column reduced from 54 to 36, 27 and $16 \mathrm{~h}$ by raising the initial o-xylene concentration from 80 to 160,240 and 360 ppmv, respectively. In UV-
ZnO/GAC column, the time of breakthrough in o-xylene removal reduced from 73 to 59,38 and $23 \mathrm{~h}$ by raising initial o-xylene concentration from 80 to 160,240 and 320 ppmv, respectively. The descending pattern of breakthrough time with the raise of initial o-xylene concentration can be related to the increased amounts of o-xylene used on each column per unit of time (Stoyanova et al., 2006). Thus, the numbers of active sites per unit of o-xylene becomes shorter at higher values of the initial concentration, leading to a more quick saturation of the column beds (Kwong et al., 2008b). However, breakthrough curves of all catalysts became sharper at higher initial o-xylene concentrations, but the appearance of breakthrough curve of UV-GAC in o-xylene elimination differed from that of other catalysts. The faster gradient of $\mathrm{C}_{t} / \mathrm{C}_{0}$ in the UV-GAC column and slower gradient of $\mathrm{C}_{t} / \mathrm{C}_{0}$ in the UV-ZnO/GAC columns caused indistinguishable concavity on the break-through curve of $\mathrm{ZnO} / \mathrm{GAC}$ catalyst. The gentler variations of $\mathrm{Ct} / \mathrm{CO}$ in the $\mathrm{ZnO} / \mathrm{GAC}$ column in comparison to that of simple GAC revealed that the $\mathrm{ZnO}$ could keep its catalytic performance in degradation of oxylene even after the breakthrough time. Thus, the saturation of the ZnO/GAC catalyst happened within a longer period of time. Moreover, there are many factors influencing the appearance of a breakthrough curve including molecular features of catalyst and contaminant, operational items such as flow rate, inlet concentration, adsorption mechanism, layer resistance and diffusion of oxylene in the sites and pores of the catalyst bed (Przepiórski et al., 2012; Vizhemehr et al., 2014; Zaitan et al., 2013).
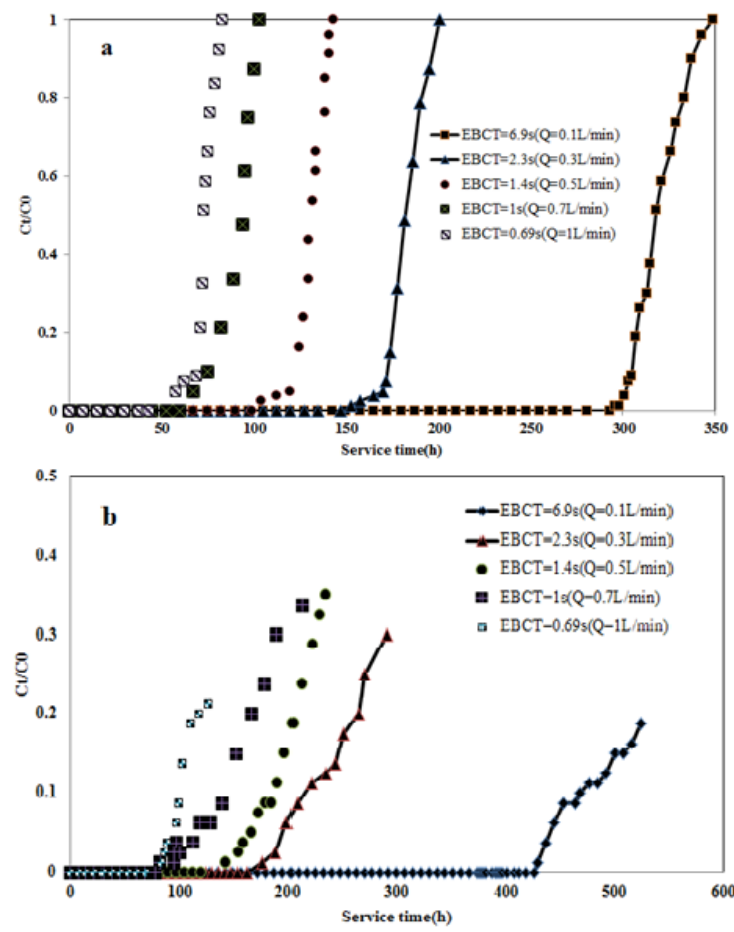

Figure 6. Influence of contact time on the performance of (a) GAC and (b)ZnO/GAC (Experimental conditions: EBCT= $0.69 \mathrm{~s} ; 1 \mathrm{~s}, 1.4 \mathrm{~s} ; 2.3 \mathrm{~s} ; 6.9 \mathrm{~s}$; initial o-xylene concentration $=80 \mathrm{ppmv}$; bed temperature $=20^{\circ} \mathrm{C}$ ) 
Based on the findings given in Fig. 5, the ZnO/GAC showed a higher removal efficiency of o-xylene than GAC at the presence of UV. It can be found that loading $\mathrm{ZnO}$ on GAC resulted in elevated catalytic efficiency of GAC up to $72.5 \%$, $64.4 \%, 57.9 \%$ and $53.6 \%$ at the initial o-xylene concentrations of 80 to 160, 240 and 360 ppmv, respectively. Based on CUR findings (calculated from Eq. (6) according to the findings depicted in Fig. 5), for treating 1.0 $\mathrm{m} 3$ polluted air containing $160 \mathrm{ppmv}$ of o-xylene, $5.1 \mathrm{~g}$ of GAC is needed, while, only $2.3 \mathrm{~g}$ of $\mathrm{ZnO} / \mathrm{GAC}$ is enough for treating $1.0 \mathrm{~m} 3$ polluted air at the same condition. Actually, by loading the catalyst $\mathrm{ZnO}$ on GAC and making impregnated GAC (ZnO/GAC) catalyst, a significant reduction was obtained in the catalyst consumption. It indicates that the presence of a small amount of $\mathrm{ZnO}$ particles (around 5\%) could significantly improve the catalytic activity of GAC in o-xylene removal.

\subsubsection{Influence of contact time}

Fig. 6 indicates the influence of residence time on the breakthrough curve of GAC and ZnO/GAC catalysts. The investigation was carried out at various flow rates between 0.1 and $1 \mathrm{~L} / \mathrm{min}$ corresponding to the EBCT of between 0.69 and $6.9 \mathrm{~s}$ with the constant o-xylene concentration and bed temperature of $80 \mathrm{ppmv}$ and $20^{\circ} \mathrm{C}$, respectively.

As shown in Fig. 6, the breakthrough time of o-xylene removal decreased from $293 \mathrm{~h}$ to $147 \mathrm{~h}, 99 \mathrm{~h}, 89 \mathrm{~h}$ and 51 $\mathrm{h}$ in UV-GAC column and from $426 \mathrm{~h}$ to $163 \mathrm{~h}, 120 \mathrm{~h}, 78 \mathrm{~h}$ and $69 \mathrm{~h}$ for UV-ZnO/GAC column by decreasing EBCT from $6.9 \mathrm{~s}$ to $2.3 \mathrm{~s}, 1.4 \mathrm{~s}, 1 \mathrm{~s}$ and $0.69 \mathrm{~s}$, respectively. The decreasing pattern of breakthrough time with the reduction of EBCT can be explained by short contact time of o-xylene molecules with UV and radicals on the catalyst surface (Jeong et al., 2005; Jeong et al., 2004). Moreover, at higher inlet air flow rates (lower EBCT), not all the oxylene molecules will have enough time to diffuse within the pore volume of the catalysts bed, ultimately resulting in shorter breakthrough time (Lillo-Ródenas et al., 2005). In other words, the treated o-xylene volume per unit of time is greater at higher flow rates (lower EBCT). Thus, earlier breakthrough happened at higher a flow rate (LilloRódenas et al., 2005; Liu et al., 2011). The breakthrough curve of GAC and $\mathrm{ZnO} / \mathrm{GAC}$ catalysts was compared indicating that $\mathrm{ZnO} / \mathrm{GAC}$ achieves a longer breakthrough time than the GAC across all of the selected residence times (Table 2) and especially at shorter residence times of 0.69 and $1 \mathrm{~s}$. Hereupon, $\mathrm{ZnO} / \mathrm{GAC}$ in comparison with GAC raised the o-xylene removal efficiency by $35 \%$ and $69 \%$ at the contact times of $2.3 \mathrm{~s}$ and $0.69 \mathrm{~s}$, respectively. It can be concluded that the $\mathrm{ZnO}$ has an efficient role for catalyzing the o-xylene degradation at the presence of UV (Changsuphan et al., 2012). The UV lamp used in this research showed a strong intensity and the produced high energy photons have an important role for the VOC degradation (Shen and Ku, 1999). The authors reported that $\mathrm{TiO}_{2}$ loaded on AC activated by UV irradiation can act as electron carriers to stop recombination of electron-hole species, which would cause greater oxidation of o-xylene in the air stream (Puma et al., 2008). Davide Barreca et al. (Barreca et al., 2009) proposed that AC loaded with a photocatalyst (such as $\mathrm{TiO} 2$ and $\mathrm{ZnO}$ ) has the potency to decompose the intermediate products in situ which will enhance the removal efficiency of the photocatalyst. In comparison with GAC, the CUR of $\mathrm{ZnO} / \mathrm{GAC}$ was much lower, although it is developed by reducing the residence time for both catalysts. For instance, the CUR for ZnO/GAC is1.6 times lower than GAC at $0.69 \mathrm{~s}$ residence time. This means that $1 \mathrm{~m} 3$ polluted air stream containing $80 \mathrm{ppmv}$ of o-xylene can be treated by $1.6 \mathrm{~g}$ of GAC at the residence time of $0.69 \mathrm{~s}$, whereas only $1 \mathrm{~g}$ of $\mathrm{ZnO} / \mathrm{GAC}$ can treat $1 \mathrm{~m} 3$ waste air at the same condition. The higher efficiency of ZnO/GAC than GAC in o-xylene removal from air stream could be associated again to the catalytic ability of the $\mathrm{ZnO}$ loaded on the surface of GAC (Changsuphan et al., 2012; Hariharan, 2006).

Table2. Catalytic potential of GAC and ZnO/GAC in adsorption and photocatalyst process at optimum conditions.

\begin{tabular}{ccccc}
\hline Item & adsorbent/catalyst & \multicolumn{3}{c}{ Process } \\
\hline & & \multirow{2}{*}{ adsorption } & photocatalyst & $\begin{array}{c}\text { catalyst } \\
\text { potential }\end{array}$ \\
\hline \multirow{2}{*}{ Breakthrough time(h) } & GAC & 53 & 60 & 13.2 \\
\cline { 2 - 5 } & ZnO/GAC & 82 & 153 & 86.5 \\
\hline
\end{tabular}

\subsubsection{Influence of the bed temperature}

The effect of bed temperature ranging from 20 to $100{ }^{\circ} \mathrm{C}$ was studied on the efficiency of catalysts at a constant flow rate of $0.7 \mathrm{~L} / \mathrm{min}$ (i.e., residence time of $1 \mathrm{~s}$ ) and constant o-xylene concentration of 80ppmv. The breakthrough curves are given in Fig. 7.

As can be seen in Fig. 7(a), the breakthrough time reduces in UV-GAC column from 51 to 46,36 and $22 \mathrm{~h}$ by raising the bed temperature from 20 to 50,80 and $100^{\circ} \mathrm{C}$, respectively. The descending pattern of breakthrough time causes decreased removal capacity of GAC column at a higher temperature (Fig. 7a). Thus, the removal capacity decreased from $1.37 \mathrm{mg} / \mathrm{g}$ to $1.21,1.01$ and $0.81 \mathrm{mg} / \mathrm{g}$ by raising the bed temperature from 20 to 50,80 and $100{ }^{\circ} \mathrm{C}$, respectively. Accordingly, the higher removal efficiency of o-xylene occurs at low temperatures in UV-GAC process. These findings have been confirmed by some studies ( $\mathrm{Wu}$ et al., 1983; Zaitan et al., 2008), which can be justified based on physical adsorption of o-xylene on the surface of GAC. Indeed, the first phase for the reaction of o-xylene with UV is the adsorption of o-xylene on the surface of catalyst. Accordingly, the physical adsorption of o-xylene molecules decreased with increasing the GAC column temperature and also the efficiency in o-xylene elimination will decline. The influence of temperature on the UVZnO/GAC system differed from that on the UV-GAC (Fig. 7(b)). As indicated in Fig. 7(b), a longer breakthrough time 
and removal capacity were obtained by raising the temperature in the bed of $\mathrm{ZnO} / \mathrm{GAC}$. The breakthrough time rose from 77 to 85,93 and $105 \mathrm{~h}$ by raising the temperature from 20 to 50,80 and $100{ }^{\circ} \mathrm{C}$, respectively. In this way, the removal capacity also raised from 1.94 to 3.12 $\mathrm{g} / \mathrm{g}$ with the increase of bed temperature from 20 to $100^{\circ} \mathrm{C}$ (Fig. 7b). This phenomenon could be attributed to the fact that at greater temperatures, the activity of $\mathrm{ZnO}$ for degradation is enhanced (Wang et al., 2012), leading to the generation of more active species (mainly $\bullet \mathrm{OH}$ ) and thereby higher o-xylene decomposition(Chen and Pignatello, 2013). The catalytic activity and radical generation potential of $\mathrm{ZnO}$ results in an increased oxylene removal in comparison with that of GAC. These findings suggest that $\mathrm{ZnO} / \mathrm{GAC}$ composite has a high performance and can be used as a catalyst for elimination of VOCs from the polluted air in a wide range of temperatures for industrial applications.
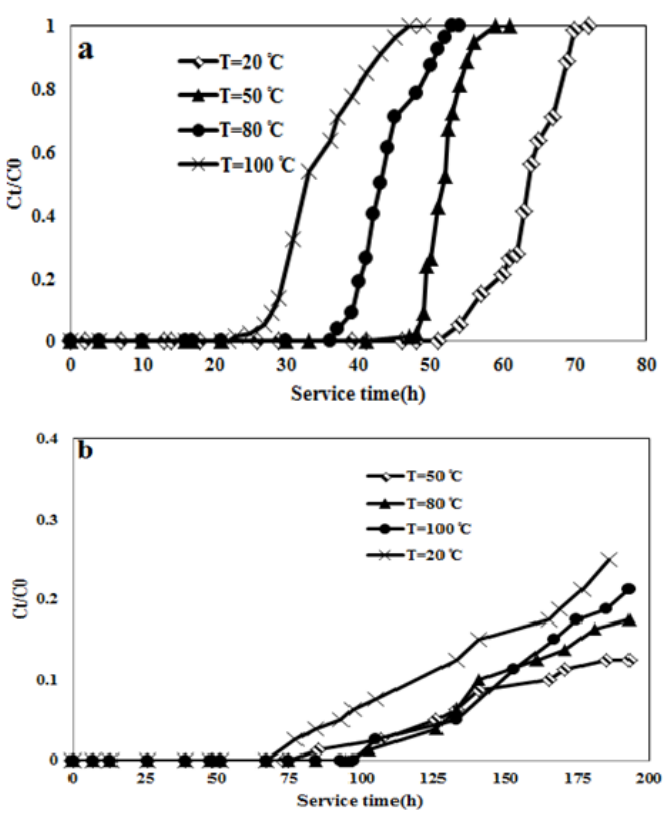

Figure 7. Influence of bed temperature on the performance of (a)GAC and (b)ZnO/GAC (Experimental conditions: $\mathrm{EBCT}=1 \mathrm{~s}$; initial o-xylene concentration $=80$ ppmv; temperature $=20,50,70,100^{\circ} \mathrm{C}$ ).

\subsection{Photocatalyst activity evaluation}

To determine the catalyst activity of GAC and ZnO/GAC, the optimum experimental conditions for each catalyst were obtained in the photocatalytic process. Afterwards, the adsorption test was carried out using GAC and $\mathrm{ZnO} / \mathrm{GAC}$ at the obtained optimum conditions in photocatalysis, but in the absence of UV.

In this way, the photocatalytic and adsorption experiments with ZnO/GAC were carried out at initial o-xylene concentration of $80 \mathrm{ppmv}$, residence time of $1 \mathrm{~s}$ and bed temperature of $100{ }^{\circ} \mathrm{C}$. Photocatalytic and adsorption tests with GAC were done at the initial o-xylene concentration of $80 \mathrm{ppmv}$, residence time of $1 \mathrm{~s}$ and bed temperature of $25{ }^{\circ} \mathrm{C}$. Eventually, the catalytic activity of GAC and Zn/GAC was calculated from Eq. (4). The photocatalyst activities of
GAC and $\mathrm{ZnO} / \mathrm{GAC}$ are summarized in Table 2. According to the information given in Table 2, and based on Eq. (4), the catalytic Photocatalyst of GAC and ZnO/GAC was obtained to be $13.2 \%$ and $86.6 \%$, respectively. Thus, the photocatalyst potential of $\mathrm{ZnO} / \mathrm{GAC}$ was 6.56 times higher than that of the GAC.

These results reveal that the influence of UV irradiation on lengthening the service time and slowing down the breakthrough time was much greater in $\mathrm{ZnO} / \mathrm{GAC}$ compared to GAC. These findings can again be attributed to the capability of $\mathrm{ZnO}$ in producing very reactive radical species. O22- (peroxide) and $\mathrm{O}-$ (atomic oxygen) radicals are the most important oxidizing species for the reaction and decomposition of VOCs (Xi et al., 2005). Furthermore, due to their high oxidation potential, hydroxyl radicals (2.8 V) would attack the bonds of VOCs and convert VOCs to more simple products such as $\mathrm{CO}_{2}$ and $\mathrm{H}_{2} \mathrm{O}$ (Shen and $\mathrm{Ku}$, 1999). Therefore, in this study hydroxyl radicals could oxidize the o-xylene molecules, thus increasing the reaction rate. The other reason for the higher catalytic potential of $\mathrm{ZnO} / \mathrm{GAC}$ also can be attributed to more active sites on the surface of $\mathrm{ZnO} / \mathrm{GAC}$ in comparison to GAC (Kurtz et al., 2004). This factor consequently contributes to greater destruction of o-xylene on the surface of $\mathrm{ZnO} / \mathrm{GAC}$.

\subsection{Fate of the o-xylene in photocatalytic process}

Desorption experiments of the GAC and ZnO/GAC were designed to determine the fate of o-xylene in photocatalytic process. The photocatalytic experiments were conducted using selected catalysts each under its optimum condition until the breakthrough time. Desorption of o-xylene and its oxidation intermediates from the GAC and $\mathrm{ZnO} / \mathrm{GAC}$ bed were carried out based on NIOSH method NO.1501 (NIOSH, 2003). GC/FID and GC/MS were applied for determination of o-xylene concentration and identification of intermediates in desorption solutions, respectively. The extent of o-xylene decomposition in photocatalytic process was obtained from mass balance analysis (MBA), based on Eq. 5 .

$$
\mathrm{M}-\mathrm{OX} \text { in }(\mathrm{mg})=\mathrm{M}-\mathrm{OX} \mathrm{Xut}_{\mathrm{ot}}(\mathrm{mg})+\mathrm{M}-\mathrm{OX} \mathrm{X}_{\mathrm{ads}}+\mathrm{M}-\mathrm{OX} \mathrm{X}_{\mathrm{dec}}
$$

Where, M-OX ${ }_{1 n}$ stands for the total mass of o-xylene entering to reactor until the breakthrough time, $\mathrm{mg}$; $\mathrm{M}$ OX $X_{\text {out }}$ is the total cumulative mass of of o-xylene in the outlet of the reactor until the breakthrough time, $\mathrm{mg}$; $\mathrm{M}$ $\mathrm{OX}_{\mathrm{ads}}$ is the mass of o-xylene desorbed from the GAC and $\mathrm{ZnO} / \mathrm{GAC}$ beds, $\mathrm{mg}$; and $\mathrm{M}-\mathrm{OX}$ dec is the mass of o-xylene decomposed in the photocatalytic process, $\mathrm{mg}$. The findings of mass balance analysis of o-xylene for the selected catalyst column are given in Table 3. As shown in Table 3, about $73.84 \%$ of the amount of o-xylene entering the GAC column can be desorbed ( $549.4 \mathrm{mg}$ ); while only $5.4 \%$ of the amount of inlet o-xylene can be desorbed $(68.26 \mathrm{mg})$ from the $\mathrm{ZnO} / \mathrm{GAC}$ column. Thus, GAC could not be used as an efficient catalyst for the photocatalytic removal of o-xylene. On the other hand, the $\mathrm{ZnO} / \mathrm{GAC}$ decomposed high amounts of o-xylene in the photocatalytic process. Accordingly, it can be found that the loading of ZnO on the GAC has effectively catalyzed the 
decomposition of O-xylene at the presence of UV. The greater catalytic capability of $\mathrm{ZnO} / \mathrm{GAC}$ in decomposing oxylene when compared with that of simple GAC can be attributed to the more active sites on the $\mathrm{ZnO}$ surface, improving the degradation of o-xylene molecules (Kandavelu et al., 2004; Zheng et al., 2008).

Table3. The findings of MBA of o-xylene in GAC and $\mathrm{ZnO} / \mathrm{GAC}$ beds at the optimum conditions

\begin{tabular}{ccc}
\hline Items & GAC & ZnO/GAC \\
\hline Initial Concentration(ppmv) & 80 & 80 \\
\hline Air flow rate(l/min) & 0.7 & 0.7 \\
\hline EBCT(s) & 1 & 1 \\
\hline Temperature $\left({ }^{\circ} \mathrm{C}\right)$ & 20 & 100 \\
\hline Breakthrough time(h) & 51 & 98 \\
\hline Inlet o-xylene (mg) & 744.03 & 1253.62 \\
\hline Outlet o-xylene (mg) & 32.19 & 61.00 \\
\hline Desorbed o-xylene (mg) & 549.45 & 68.26 \\
\hline Decomposed o-xylene ${ }^{\mathrm{a}}(\mathrm{mg})$ & 162.34 & 1124.32 \\
\hline Desorbed ratio (\%) & 73.84 & 5.4 \\
\hline Decomposed ratio (\%) & 21.81 & 89.68 \\
\hline
\end{tabular}

aDecomposed o-xylene $=$ inlet o-xylene $(\mathrm{mg})-($ outlet + desorbed $)$ mass of o-xylene (mg).
In order to obtain a better insight into the o-xylene degradation by GAC and $\mathrm{ZnO} / \mathrm{GAC}$ in the photocatalytic process, the major intermediates were identified according to different retention times in the GC/MS spectrums of the desorption solutions of o-xylene and intermediates from the GAC and ZnO/GAC beds. The byproducts of o-xylene in the photocatalytic degradation process of GAC and ZnO/GAC composites are given in Table 4. As indicated in Table 4, moreover the o-xylene as the parent compound and $\mathrm{CS}_{2}$ as the solvent, the major byproducts desorbed from GAC were methanoic acid, phenylmethanal, o-nitrop-cresol and methyl-di-phenyl-methane; whereas the main byproducts desorbed from ZnO/GAC were methanoic acid, o-xylene and methyl-di-phenyl-methane. These compounds have probably originated from inadequate reactions of active species and o-xylene in the photocatalytic process (Paul et al., 2007). These compounds have gradually filled the active sites and cause the catalyst to be deactivated (Rezaei and Soltan, 2012). The comparison between the intermediates of the two catalysts indicates that higher and greater byproducts were found in o-xylene degradation using the UV-GAC than with UV-ZnO/GAC.

Table4. The byproducts of o-xylene in the photocatalytic degradation process of GAC and ZnO/GAC composites

\begin{tabular}{|c|c|c|c|}
\hline Catalyst & Compounds & Retention time (min) & Molecular weight $(\mathrm{g} / \mathrm{mol})$ \\
\hline \multirow{10}{*}{$\begin{array}{l}\text { Desorbed } \\
\text { intermediate } \\
\text { species from } \\
\text { GAC catalyst }\end{array}$} & Methanoic acid & 1.27 & 46.03 \\
\hline & Carbon disulphide & 2.01 & 76.14 \\
\hline & O-xylene & 8.23 & 106.16 \\
\hline & Phenylmethanal & 11.41 & 106.12 \\
\hline & Chlorophenylmethane & 12.47 & 126.58 \\
\hline & Phenylcarbinol & 12.98 & 108.14 \\
\hline & Phenyl-methyl ester & 13.39 & 150.18 \\
\hline & O-nitro-p-cresol & 14.21 & 153.14 \\
\hline & Methyl-di-phenyl-methane & 16.41 & 168.24 \\
\hline & Carboxybenzene & 17.52 & 122.12 \\
\hline \multirow{5}{*}{$\begin{array}{l}\text { Desorbed } \\
\text { intermediate } \\
\text { species from } \\
\text { ZnO/GAC } \\
\text { catalyst }\end{array}$} & Methanoic acid & 1.34 & 46.03 \\
\hline & Carbon disulphide & 2.91 & 76.14 \\
\hline & O-xylene & 8.36 & 106.16 \\
\hline & Phenylmethanal & 11.52 & 106.12 \\
\hline & Methyl-di-phenyl-methane & 16.44 & 168.24 \\
\hline
\end{tabular}

\section{Conclusion}

In this study, application of GAC and ZnO immobilized on GAC was studied for photocatalytic removal of o-xylene from waste air stream. The synthesized photocatalysts were characterized by of FT-IR, XRD, SEM and EDX. The results showed greater photocatalytic activity of the ZnO/GAC in comparison with its plain counterpart. The photocatalytic degradation of o-xylene decreased with the increase of initial concentration and flow rate for both GAC and $\mathrm{ZnO} / \mathrm{GAC}$. The removal of o-xylene increased with elevation of the bed temperature by using $\mathrm{ZnO} / \mathrm{GAC}$, whereas it decreased by using GAC. The optimal temperatures for o-xylene removal were obtained as $20^{\circ} \mathrm{C}$ and $100{ }^{\circ} \mathrm{C}$ for GAC and $\mathrm{ZnO} / \mathrm{GAC}$, respectively. $\mathrm{ZnO} / \mathrm{GAC}$ decomposed $86 \%$ of o-xylene in the presence of UV, while GAC could decompose only $15 \%$ of o-xylene in the same condition. It can be concluded that the $\mathrm{ZnO} / \mathrm{GAC}$ is a good and promising option with a high catalytic potential activity which can be used for photocatalytic abatement of aromatic VOCs from polluted air streams.

\section{Acknowledgments}

This work was conducted as a PhD student project of Hossein Arfaeinia. Authors gratefully acknowledge the Iran University of Medical Sciences for providing financial and instrumental support to conduct this work (Grant No: 94-01-27-25738).

\section{References}

Adjimi S., Sergent N., Roux J-C., Delpech F., Pera-Titus M., Chhor K., Kanaev A. and Thivel P-X. (2014), Photocatalytic paper based on sol-gel titania nanoparticles immobilized on porous silica for VOC abatement, Applied Catalysis B: Environmental. 154, 123-133. 
An HTQ., Huu TP., Le Van T., Cormier JM. and Khacef A. (2011), Application of atmospheric non thermal plasma-catalysis hybrid system for air pollution control: Toluene removal, Catalysis today. 176, 474-477.

Ao C. and Lee S. (2005), Indoor air purification by photocatalyst TiO 2 immobilized on an activated carbon filter installed in an air cleaner, Chemical engineering science. 60, 103-109.

Arfaeinia H., Moradi M., Sharafi K., Mahdi Esfahan N. and Dobaradaran S. (2015), Evaluation of Public Health Impacts Related To Urban Air Pollution In Shiraz And Bushehr, Iran, International Journal of Pharmacy \& Technology. 7, 9811-9824.

Arfaeinia H., Sharafi K., Banafshehafshan S. and Hashemi S.E. (2016), Degradation and biodegradability enhancement of chloramphenicol and azithromycin in aqueous solution using heterogeneous catalytic ozonation in the presence of MGO nanocrystalin comparison with single ozonation, International Journal Of Pharmacy \& Technology. 8, 10931-10948.

Assadi A., Palau J., Bouzaza A. and Wolbert D. (2013), A continuous air reactor for photocatalytic degradation of isovaleraldehyde: effect of different operating parameters and chemical degradation pathway, Chem Eng Res Des. 91, 1307-1316.

Assadi AA., Palau J., Bouzaza A., Penya-Roja J., Martinez-Soriac V. and Wolbert D. (2014), Abatement of 3-methylbutanal and trimethylamine with combined plasma and photocatalysis in a continuous planar reactor, Journal of Photochemistry and Photobiology A: Chemistry. 282, 1-8.

Auvinen J. and Wirtanen L. (2008), The influence of photocatalytic interior paints on indoor air quality, Atmospheric Environment. 42, 4101-4112.

Barreca D., Gasparotto A., Maccato C., Tondello E., Štangar UL. and Patil SR. (2009), Photoinduced superhydrophilicity and photocatalytic properties of $\mathrm{ZnO}$ nanoplatelets, Surface and Coatings Technology. 203, 2041-2045.

Barzegar A., Mortazavi B., Asilian H. and Kazemian H. (2014), Catalytic degradation of toluene by manganese oxide catalyst loaded on a natural zeolite support, Scientific Journal of Review. 3, 345-352.

Boulinguiez B. and Le Cloirec P. (2010), Adsorption on Activated Carbons of Five Selected Volatile Organic Compounds Present in Biogas: Comparison of Granular and Fiber Cloth Materials ${ }^{\dagger}$, Energy \& Fuels. 24, 4756-4765.

Bouzaza A., Vallet C. and Laplanche A. (2006), Photocatalytic degradation of some VOCs in the gas phase using an annular flow reactor: determination of the contribution of mass transfer and chemical reaction steps in the photodegradation process, Journal of Photochemistry and Photobiology A: Chemistry. 177, 212-217.

Candal R.J., Zeltner W.A. and Anderson M.A. (2000), Effects of pH and applied potential on photocurrent and oxidation rate of saline solutions of formic acid in a photoelectrocatalytic reactor, Environ.Sci.Technol., 34, 3443-3451.

Changsuphan A., Wahab MIB. and Oanh NTK. (2012), Removal of benzene by $\mathrm{ZnO}$ nanoparticles coated on porous adsorbents in presence of ozone and UV, Chemical Engineering Journal. 181, 215-221.

Chen C-Y. and Pignatello JJ. (2013), Catalytic oxidation for elimination of methyl bromide fumigation emissions using ceria-based catalysts, Applied Catalysis B: Environmental. 142, 785-794.
Choi W., Ko JY., Park H. and Chung JS. (2001), Investigation on TiO 2-coated optical fibers for gas-phase photocatalytic oxidation of acetone, Applied Catalysis B: Environmental. 31, 209-220.

Danion A., Disdier J., Guillard C., Abdelmalek F. and JaffrezicRenault N. (2004), Characterization and study of a single-TiO 2-coated optical fiber reactor, Applied Catalysis B: Environmental. 52, 213-223.

Darvishi Cheshmeh Soltani R., Rezaee A. and Khataee A. (2013), Combination of carbon black-ZnO/UV process with an electrochemical process equipped with a carbon black-PTFEcoated gas-diffusion cathode for removal of a textile dye, Industrial \& Engineering Chemistry Research. 52, 1413314142.

Das D., Gaur V. and Verma N. (2004), Removal of volatile organic compound by activated carbon fiber, Carbon. 42, 2949-2962.

Ding Z., Hu X., Yue PL., Lu GQ. and Greenfield PF. (2001), Synthesis of anatase TiO 2 supported on porous solids by chemical vapor deposition, Catalysis today. 68, 173-182.

Dunn RF. and El-Halwagi MM. (1994), Optimal design of multicomponent VOC condensation systems, Journal of hazardous materials. 38, 187-206.

El-Sheikh AH., Newman AP., Al-Daffaee H., Phull S., Cresswell N. and York S. (2004), Deposition of anatase on the surface of activated carbon, Surface and Coatings Technology. 187, 284292.

EPA. Toxicological profile for toluene, First ed., EPA, 2006.

Gaur V., Sharma A. and Verma N. (2005), Catalytic oxidation of toluene and $\mathrm{m}$-xylene by activated carbon fiber impregnated with transition metals, Carbon. 43, 3041-3053.

Granda M., Santamaría R., Menéndez R. and Radovic L (2003). Chemistry and Physics of Carbon. Marcel Dekker: New York.

Hariharan C. (2006), Photocatalytic degradation of organic contaminants in water by $\mathrm{ZnO}$ nanoparticles: revisited, Applied Catalysis A: General. 304, 55-61.

Herbig B. and Löbmann P. (2004), TiO 2 photocatalysts deposited on fiber substrates by liquid phase deposition, Journal of Photochemistry and Photobiology A: Chemistry. 163, 359-365.

Ichiura H., Kitaoka T. and Tanaka H. (2002), Preparation of composite TiO2-zeolite sheets using a papermaking technique and their application to environmental improvement Part I Removal of acetaldehyde with and without UV irradiation, Journal of materials science. 37, 2937-2941.

Jeong J., Sekiguchi K., Lee W. and Sakamoto K. (2005), Photodegradation of gaseous volatile organic compounds (VOCs) using TiO 2 photoirradiated by an ozone-producing UV lamp: decomposition characteristics, identification of byproducts and water-soluble organic intermediates, Journal of Photochemistry and Photobiology A: Chemistry. 169, 279-287.

Jeong J., Sekiguchi K. and Sakamoto K. (2004), Photochemical and photocatalytic degradation of gaseous toluene using shortwavelength UV irradiation with TiO 2 catalyst: comparison of three UV sources, Chemosphere. 57, 663-671.

Kandavelu V., Kastien H. and Thampi KR. (2004), Photocatalytic degradation of isothiazolin-3-ones in water and emulsion paints containing nanocrystalline TiO 2 and $\mathrm{ZnO}$ catalysts, Applied Catalysis B: Environmental. 48, 101-111.

Kibanova D., Cervini-Silva J. and Destaillats H. (2009), Efficiency of clay- $\mathrm{TiO}_{2}$ nanocomposites on the photocatalytic elimination of a model hydrophobic air pollutant, Environ.Sci.Technol., 43, 1500-1506. 
Kurtz M., Bauer N., Büscher C., Wilmer H., Hinrichsen O., Becker R., Rabe S., Merz K., Driess M. and Fischer RA. (2004), New synthetic routes to more active $\mathrm{Cu} / \mathrm{ZnO}$ catalysts used for methanol synthesis, Catalysis Letters. 92, 49-52.

Kwong C., Chao CY., Hui K. and Wan M. (2008a), Removal of VOCs from indoor environment by ozonation over different porous materials, Atmospheric Environment. 42, 2300-2311.

Kwong C., Chao CYH., Hui K. and Wan M. (2008b), Catalytic ozonation of toluene using zeolite and MCM-41 materials, Environ.Sci.Technol., 42, 8504-8509.

Le Cloirec P. and Germinet R (1998). "Les composés organiques volatils (COV) dans l'environnement," Lavoisier Technique \& documentation.

Lillo-Ródenas M., Cazorla-Amorós D. and Linares-Solano A. (2005), Behaviour of activated carbons with different pore size distributions and surface oxygen groups for benzene and toluene adsorption at low concentrations, Carbon. 43, 1758-1767.

Liu H., Wang X., Zhai G., Zhang J., Zhang C., Bao N. and Cheng C. (2012), Preparation of activated carbon from lotus stalks with the mixture of phosphoric acid and pentaerythritol impregnation and its application for Ni (II) sorption, Chemical engineering journal, 209, 155-162.

Liu J., Yan Y. and Zhang H. (2011), Adsorption dynamics of toluene in composite bed with microfibrous entrapped activated carbon, Chemical Engineering Journal. 173, 456-462.

Maldonado-Hódar FJ. (2011), Removing aromatic and oxygenated VOCs from polluted air stream using Pt-carbon aerogels: Assessment of their performance as adsorbents and combustion catalysts, Journal of hazardous materials, 194, 216-222.

Mirzaei N., Arfaeinia H., Moradi M., Mohammadi F.M., Velayati, A. and Sharafi K. (2016), The statistical analysis of seasonal and time variations on trend of important air pollutants $\left(\mathrm{SO}_{2}\right.$, $\mathrm{O}_{3}, \mathrm{NO}_{\mathrm{x}}, \mathrm{CO}, \mathrm{PM}_{10}$ )-in Western Iran: a case study, International Journal of Pharmacy and Technology 7, 9610-9622.

Mo J., Zhang Y., Xu Q., Lamson JJ. and Zhao R. (2009), Photocatalytic purification of volatile organic compounds in indoor air: a literature review, Atmospheric Environment. 43, 2229-2246.

NIOSH. (2003), , Hydrocarbons, aromatic: method 1501, in: N. S. P (Ed.), Department ofHealth and Human Services P. H. S., Centers for Disease Control, Nationallnstitute for Occupational Safety and Health, DHHS, Publication. 1-7.

Özçelik Z., Soylu GSP. and Boz İ. (2009), Catalytic combustion of toluene over $\mathrm{Mn}$, Fe and Co-exchanged clinoptilolite support, Chemical Engineering Journal. 155, 94-100.

Patterson A. (1939), The Scherrer formula for X-ray particle size determination, Physical review. 56, 978.

Paul T., Miller PL. and Strathmann TJ. (2007), Visible-lightmediated $\mathrm{TiO} 2$ photocatalysis of fluoroquinolone antibacterial agents, Environ.Sci.Technol., 41, 4720-4727.

Pichat P., Disdier J., Hoang-Van C., Mas D., Goutailler G. and Gaysse C. (2000), Purification/deodorization of indoor air and gaseous effluents by TiO 2 photocatalysis, Catalysis today, 63, 363-369.

Przepiórski J., Czyżewski A., Kapica J., Moszyński D., Grzmil B., Tryba B., Mozia S. and Morawski A. (2012), Low temperature removal of SO 2 traces from air by MgO-loaded porous carbons, Chemical Engineering Journal, 191, 147-153.
Puma GL., Bono A., Krishnaiah D. and Collin JG. (2008), Preparation of titanium dioxide photocatalyst loaded onto activated carbon support using chemical vapor deposition: A review paper, Journal of hazardous materials, 157, 209-219.

Rezaei E. and Soltan J. (2012), Low temperature oxidation of toluene by ozone over $\mathrm{MnOx} / \mathrm{Y}$-alumina and $\mathrm{MnOx} / \mathrm{MCM}-41$ catalysts, Chemical Engineering Journal, 198, 482-490.

Shen Y-S. and Ku Y. (1999), Treatment of gas-phase volatile organic compounds (VOCs) by the $\mathrm{UVO}_{3}$ process, Chemosphere, 38, 1855-1866.

Shepherd A. (2001), Activated carbon adsorption for treatment of VOC emissions, 13th Annual EnviroExpo, Boston.

Shirzad-Siboni M., Khataee A., Vahid B. and Joo SW. (2015), Synthesis, Characterization and Immobilization of $\mathrm{ZnO}$ Nanosheets on Scallop Shell for Photocatalytic Degradation of an Insecticide, Science of Advanced Materials, 7, 806-814.

Stoyanova M., Konova P., Nikolov P., Naydenov A. and Mehandjiev D. (2006), Alumina-supported nickel oxide for ozone decomposition and catalytic ozonation of CO and VOCs, Chemical Engineering Journal, 122, 41-46.

Tunsaringkarn T., Siriwong W., Rungsiyothin A. and Nopparatbundit S. (2012), Occupational exposure of gasoline station workers to BTEX compounds in Bangkok, Thailand, The international journal of occupational and environmental medicine. 3.

Uddin M., Cesano F., Bonino F., Bordiga S., Spoto G., Scarano D. and Zecchina A. (2007), Photoactive $\mathrm{TiO}_{2}$ films on cellulose fibres: synthesis and characterization, Journal of Photochemistry and Photobiology A: Chemistry, 189, 286-294.

Vizhemehr AK., Haghighat F. and Lee C-S. (2014), Gas-phase filters breakthrough models at low concentration-Effect of relative humidity, Building and Environment. 75, 1-10.

Wang J., Wang Z., Huang B., Ma Y., Liu Y., Qin X., Zhang X. and Dai $Y$. (2012), Oxygen vacancy induced band-gap narrowing and enhanced visible light photocatalytic activity of $\mathrm{ZnO}$, ACS applied materials \& interfaces. 4, 4024-4030.

Wang X., Jia X. and Wen J. (2010), Transient modeling of toluene waste gas biotreatment in a gas-liquid airlift loop reactor, Chemical Engineering Journal. 159, 1-10.

Wu JC-S. and Chang T-Y. (1998), VOC deep oxidation over Pt catalysts using hydrophobic supports, Catalysis today, 44, 111-118.

Wu P., Debebe A. and Ma YH. (1983), Adsorption and Diffusion of C 6 and C 8 Hydrocarbons in Silicalite, Zeolites. 3, 118-122.

Xi Y., Reed C., Lee Y-K. and Oyama ST. (2005), Acetone oxidation using ozone on manganese oxide catalysts, The Journal of Physical Chemistry B, 109, 17587-17596.

Zaitan H., Bianchi D., Achak O. and Chafik T. (2008), A comparative study of the adsorption and desorption of o-xylene onto bentonite clay and alumina, Journal of Hazardous Materials. 153, 852-859.

Zaitan H., Korrir A., Chafik T. and Bianchi D. (2013), Evaluation of the potential of volatile organic compound (di-methyl benzene) removal using adsorption on natural minerals compared to commercial oxides, Journal of hazardous materials, 262, 365-376.

Zheng Y., Chen C., Zhan Y., Lin X., Zheng Q., Wei K. and Zhu J. (2008), Photocatalytic activity of Ag/ZnO heterostructure nanocatalyst: correlation between structure and property, The Journal of Physical Chemistry C. 112, 10773-10777. 